\title{
Integrating psychoeducation in a basic computer skills course for people suffering from social anxiety: participants' experiences
}

This article was published in the following Dove Press journal:

Journal of Multidisciplinary Healthcare

10 August 2011

Number of times this article has been viewed

\section{Hildegard D Löhr ${ }^{1,2}$ \\ Jan H Rosenvinge ${ }^{1,3}$ \\ Rolf Wynn 2,4}

'Division of General Psychiatry, University Hospital of North

Norway, ${ }^{2}$ Telemedicine Research

Group, Department of Clinical

Medicine, Faculty of Health Sciences,

${ }^{3}$ Department of Psychology, Faculty of

Health Sciences, University of Tromsø,

${ }^{4}$ Division of Addiction and Specialized

Psychiatry, University Hospital of

North Norway, Tromsø, Norway
Correspondence: Rolf Wynn

UNN-Åsgård, N-929I Tromsø, Norway

Tel +47 77620888

Fax +47 77627532

Email rolf.wynn@gmail.com
Abstract: We describe a psychoeducational program integrated in a basic computer skills course for participants suffering from social anxiety. The two main aims of the course were: that the participants learn basic computer skills, and that the participants learn to cope better with social anxiety. Computer skills were taught by a qualified teacher. Psychoeducation and cognitive therapy skills, including topics such as anxiety coping, self-accept, and self-regulation, were taught by a clinical psychologist. Thirteen of 16 participants completed the course, which lasted 11 weeks. A qualitative analysis was performed, drawing on observations during the course and on interviews with the participants. The participants were positive about the integration of psychoeducation sessions in the computer course, and described positive outcomes for both elements, including improved computer skills, improved self-esteem, and reduced social anxiety. Most participants were motivated to undertake further occupational rehabilitation after the course.

Keywords: cognitive therapy, information technology, occupational rehabilitation, psychoeducation, self-help, social anxiety

\section{Introduction}

\section{Social anxiety}

During their lifetime, about $13 \%$ of Norwegians will suffer from social anxiety. ${ }^{1}$ It is the most common of all anxiety disorders, and has the lowest rates of spontaneous recovery. ${ }^{2}$ Without treatment social anxiety often becomes chronic. ${ }^{3}$ Comorbidity is remarkably high. ${ }^{4-6}$ Social anxiety is especially associated with depression, ${ }^{4,6}$ but also with bipolar disorder, obsessive compulsive disorder, agoraphobia with and without panic disorder, ${ }^{7}$ substance use, ${ }^{8}$ and risk-prone behaviors. ${ }^{9}$ Help-seeking behavior is low compared with other anxiety disorders or affective disorders, and contact with mental health services is often not established before secondary problems occur. ${ }^{5,7}$ The economic burden of social anxiety seems to be substantial for individuals, the health services, ${ }^{10}$ and society in general. ${ }^{5,11}$ Many clients with social anxiety drop out of occupational rehabilitation, and some may be permanently unable to work. ${ }^{10,12}$ Many would like to return to a job or to school, but fear of failing makes them ambivalent about doing so. ${ }^{13}$ Therapy is not always available, especially in rural districts. Moreover, ordinary occupational rehabilitation services may not have the specific competence required to support people with social anxiety.

\section{Social anxiety and cognitive behavioral therapy}

Cognitive behavioral therapy (CBT) has proved effective for the treatment of social anxiety, ${ }^{14,15}$ yet to our knowledge, no studies have examined occupational rehabilitation 
as a success criterion for the treatment of this condition by means of CBT. Nonetheless, interventions based on CBT integrated in occupational training for people with schizophrenia ${ }^{16}$ and chronic low back pain ${ }^{17}$ have showed positive effect.

Attention focus is a central term in CBT of anxiety. ${ }^{18,19}$ Attention is essential to success at school and at work, to move the focus between the task and one's own resources, and social relations for mutual support. These demands correspond with 2 dimensions of social anxiety, achievement anxiety and interaction anxiety (Figure 1). 'Achievement anxiety' is task orientated and reflects the person's negative assumptions about his or her own performance skills, and expectation of negative evaluation by others. 'Interaction anxiety' refers to a person's belief that others generally will think negatively of him or her. People with longstanding social anxiety and disability may struggle on both dimensions.

Typical social fears are: ${ }^{7}$ meeting people and not knowing what to say, thinking you might sound foolish especially if you ask for help, writing while being observed, talking in front of a small group or in public, eating or drinking in public places, and using public toilets. All these social fears may easily be triggered in an educational or occupational setting. Thus, a computer school should provide excellent exercise conditions for people with social anxiety.

\section{CBT models for social anxiety}

The two pre-eminent cognitive behavioral models for social anxiety differ in their assumptions on attention focus. Clark and Wells ${ }^{18}$ claim that individuals with social anxiety get locked in a negative self-focus, with negative thinking and imagination based essentially on internal information.

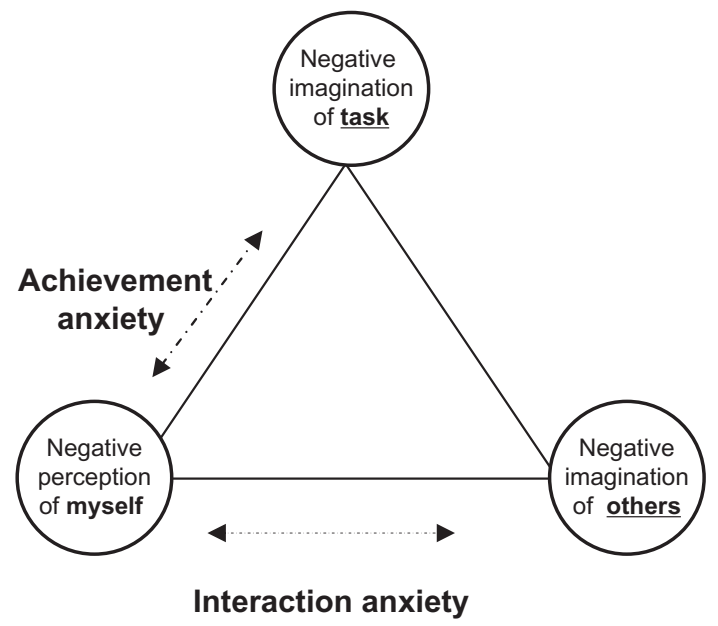

Figure I Attention focus and 2 dimensions of social anxiety.
Excessive self-focus inhibits the individual's external focus on contextual interpersonal information. A crucial treatment point is that the client learns to focus on the surroundings in order to get external social information. In contrast, Rapee and Heimberg ${ }^{19}$ assert that socially anxious persons are vigilant with respect to any contextual threat, and that they have both an internal and an external attention focus. According to our experience, clients exhibiting either type of attention focus can be found in a group with heterogeneous comorbidity.

In several cognitive models, both the attention training elements of 'mindfulness' as well as 'meta-cognition' are essential concepts to change ingrained dysfunctional cognitive and behavioral patterns. ${ }^{20}$ Mindfulness is also a central aspect of learning basic self-regulating skills such as emotion regulation. Being mindful, means to observe, describe, and accept current external and internal events in a detached manner before deciding on the appropriate action. The detached aspect of mindfulness is important in order to recognize specific dysfunctional patterns of one's cognitive processing. 'Meta-cognition' involves being attentive to one's cognitive processing, and able to discuss and change dysfunctional patterns. In particular, this involves the ability to actively choose or shift attention focus. Learning this skill is essential in meta-cognitive therapies. ${ }^{20}$

\section{Adaptations of CBT manuals for heterogeneous groups}

Ethical and practical reasons have to be considered when adapting the cognitive model to real life. First of all, while attending school, the participants are actually students, and to call them patients or clients could be perceived as stigmatizing. Next, applying a standardized treatment manual to a student in a classroom could easily be perceived negatively, especially by socially anxious people. Furthermore, CBT has been developed for clinical settings, and the therapist is expected to follow specific manuals developed for different diagnoses. The manuals are typically composed of a complex set of procedures, and it may be difficult if not impossible to follow a specific treatment manual in a classroom setting with a substantially heterogeneous group. Teaching a dimensional understanding in terms of biopsychosocial variables on a continuum from functional to dysfunctional may be more appropriate for a heterogeneous group, and also allow the participants to identify sub-threshold functioning. ${ }^{21}$ Participants may then recognize that they face a particular challenge to a larger or smaller degree. In this type of treatment of social anxiety, mindfulness and meta-cognitive 
perspectives can also be introduced, and may function as important tools for self-regulation. ${ }^{20}$

\section{Why integrate psychoeducation in a basic computer skills course?}

Basic computer skills are essential for participation in modern society, for instance to get access to information and to communicate with institutions such as banks, occupational authorities, and schools. ${ }^{22}$ Access to the Internet may reduce social isolation and increase self-esteem for people suffering from social anxiety. ${ }^{23,24}$ Furthermore, it has been suggested that email used as a supplement to psychotherapy for social anxiety can facilitate processes essential for face-to-face contact. ${ }^{25}$ In Norway, patients suffering from social anxiety and isolation may get a PC funded by public social insurance. However, not all clients are able or have the opportunity to learn the necessary computer skills by themselves.

The use of the Internet may have both positive and negative health outcomes, depending on who uses it and for what purpose. Some studies have shown a correlation between Internet addiction and ADHD, hostility, and depression. ${ }^{26}$ However, it seems as though people with social anxiety tend to use the Internet for rehearsal of psychosocial skills. ${ }^{27}$ Moreover, a longitudinal study over 3 years found that depressive people get more depressed when looking for health information on the Internet, whereas those using the Internet for communication with family and friends were less depressed after 3 years. ${ }^{28}$

How may a basic computer course facilitate coping with social anxiety? Attending a course 4 half days a week is probably an enormous challenge after years without any sort of occupation. Because regular training is crucial for establishing new habits, arranging more days on than off school may be important. Computer tasks and progression should be adapted to individual needs, particularly when the participating groups are heterogeneous. During our course, no formal competence test was given, and final tests were deliberately dropped in order to avoid triggering achievement anxiety among the participants.

As an interactive medium, the computer can represent a safe place during the course. It easily attracts attention, and curiosity about and interest in the computer may reduce time spent on the negative self-focus commonly observed among people with social anxiety. Identifying and starting these processes could be an effective and appropriate way to help people with social anxiety to integrate a more functional cognitive model of self understanding and understanding of their illness. Moreover, some cognitive processes common to both human-computer interaction and good interpersonal interaction may be important, eg, step-by-step processing, turn-taking, systematic problem solving, as well as trialand-error with immediate feedback.

\section{Aims of the course}

The present study addressed the following research questions:

- Do individuals with longstanding social anxiety report benefits from an 11 week computer course including psychoeducation and CBT?

- Do participants wish to continue with occupational rehabilitation after completing the course?

\section{Materials and methods}

\section{The participants}

The project was approved by the Regional Medical Ethics Committee and all participants signed an informed consent form. People suffering from social anxiety could be included in the study. Exclusion criteria were a high suicidal risk, psychotic symptoms, or a current addiction problem. Nineteen participants were recruited; 3 resigned a few days before or after starting. Thus, 16 people aged 20 to 53 years, 5 male and 11 female, agreed to participate in the study. Three dropped out half way through the course, but met for the final interview. There were 7 completers in the first group ( 2 male, 5 female), and 6 completers in the second group (one male, 5 female). About half were living with a partner and/or children. The educational level of the completers was varied; 5 had only the compulsory 9 years of school, 7 had completed high school, while 1 had a college education. Their work experience varied from none to leadership level. All the participants had been on a disability allowance for 1 to 25 years, due to longstanding psychiatric problems. Five were on a permanent disability allowance. Computer skills ranged from none (some were computer phobic) to certain formal qualifications, but most used a computer only sparingly; $60 \%$ reported having a $\mathrm{PC}$ at home.

A DSM-IV ${ }^{29}$ diagnostic evaluation showed a considerable comorbidity in terms of post-traumatic stress disorder (PTSD), generalized anxiety disorder (GAD), panic disorder, recurrent depression, bipolar disorder in remission, and personality disorders, notably of an avoidant, paranoid, or borderline form. Diagnostically, there is considerable overlap between avoidant personality disorder and social anxiety disorder. ${ }^{30}$ Some participants had been or were currently in treatment elsewhere, and 3 were already familiar with CBT. 


\section{The intervention}

A course called 'Anxiety coping by learning basic computer skills' was designed in cooperation between a clinical psychologist (the first author) and a local private computer school providing services to private companies as well as to the local branch of the Norwegian Labour and Welfare Administration (NAV). The course had 2 main aims for the participants: to learn basic computer skills and to learn how to cope better with social anxiety. The latter objective was addressed by teaching the participants about anxiety, self-acceptance, and self-regulation. Elements from CBT, metacognitive techniques, and mindfulness exercises were also used.

\section{Procedure}

The participants were recruited from the city where the study took place. Information about the project was given to the local psychiatric outpatient clinic, to all the GPs' offices in the city, and to the local office of the Labour and Welfare administration. Information about the project was posted at these places and potential participants were given oral and written information by the professionals (eg, therapists, GPs, social workers). When someone expressed an interest in participating in the study, the name and contact information were forwarded to the clinical psychologist in charge of the study. The first contact with the psychologist was planned carefully, to increase the client's feeling of being safe. Thus, the first contact with the client was a text message (SMS), informing the client about the referral and asking for a telephone call to set up a face-to-face meeting. The intention was to provide an initial distant conversation. Before the meeting, a formal standard letter was sent to the client, with the invitation as well as information about the course and the research procedures. Following the initial meeting, 1 to 2 interviews were conducted, where motivation was assessed and the participant could discuss individual challenges.

The participants were assigned to 2 parallel classes with 8 students each, one class meeting at school before noon, the other after noon. In the classroom, the desks were placed in a horseshoe shape. Each student borrowed a laptop from the school. Both the horseshoe placement of the desks and the laptop (ie, as an alternative to a large stationary computer) were chosen to facilitate face-to-face communication in the group.

The participants attended school 3 and a half hours per day, 4 days a week. The duration of the course was 11 weeks, the usual length for basic computer skills courses at that school. Three quarters of the time was spent on computer skills taught by a teacher, and one quarter on psychoeducation taught by a clinical psychologist. The computer tasks were individually adapted to the participants' coping level. The psychologist assisted only with current problems related to the course. Individually tailored psychosocial exercises were designed with each student during an individual session with the psychologist, based on the initial assessment. Individual problems could be discussed in the classroom if the topic was relevant to the other participants. The computer skills teacher also attended the psychoeducation sessions, to gain a good understanding of the processes in the group and to be able to support the students practicing new psychosocial skills during computer lessons. Illustrations were used to depict psychological phenomena and processes in order to facilitate psychoeducation, self-help, goal-definition, and motivation for change. Also, the figures could serve as a reminder for a set of essential CBT concepts like 'emotional temperature', the 'panic circle' and mechanisms of emotion-regulation in terms of cognitive restructuring, problem solving, detached mindfulness, and functional focusing. Techniques for limiting rumination and worries and for activity planning and mindful sensing were also illustrated.

\section{Data collection and analysis}

In this article, we present findings from observations during the course, as well as semi-structured interviews with the participants and the computer skills teacher. The interviews focused on motives for attending the course, how the participants evaluated the combination of a computer skills course and social anxiety training, how they experienced the school milieu, and what the participants perceived to be the potential benefits and disadvantages after completion of the course. The first author conducted all the interviews, which were recorded. A qualitative analysis was performed, drawing on notes and observations made during the course and during the interviews. In the analysis, central topics and ideas that occurred in the data were identified, sorted, and condensed. ${ }^{31}$ Below, we present a synthesis of the observations and the interviews. We have included some quotations to illustrate the main points. All the names used are pseudonyms.

\section{Results}

\section{Participants' objectives for the course}

Some participants were primarily interested in learning basic computer skills, but would not have dared to attend without the special psychosocial support given in this course. Others were primarily motivated to learn different kinds of anxiety coping, and they regarded participating in a basic 
computer course as an arena for learning how to obtain psychosocial skills.

\section{Participants' reactions to the psychoeducation sessions}

The 'psychologist's day' with psychoeducation and corresponding exercises was highly appreciated by most participants. However, a few did not like to talk about feelings at all. They chose either not to attend school on that particular day, or they had special arrangements allowing them to leave the lesson. They later dropped out of the course, while one completed the course without attending the psychoeducation sessions. All those who appreciated psychoeducation preferred that anxiety coping was taught in the classroom and not separately in a therapy group. Most were relieved by learning that anxiety and other negative feelings were basically normal signals which may escalate to stressing 'disorders' when not accepted and worked through but instead suppressed or neglected. Learning how to regulate normal negative feelings such as anxiety gave them a sense of normality and self-confidence. Some became angry and upset, asking why nobody had explained anxiety to them before. A typical statement was: 'Why didn't we learn this at school? If everyone had learned this - my life would have been different.'

\section{Perceived benefits of integrating psychoeducation in a computer skills course}

All the completers reported better self-esteem by attending a computer course at a 'normal' school. This was regarded as status raising. Thus they learned how to participate in the computer society, and could tell others that they were attending a computer course. Even one student who opted out of the psychoeducation sessions said she enjoyed being part of the group because she felt understood and accepted there. The status aspect appeared independent of the level of computer skills. Many said it motivated them to continue in the course, especially during the first weeks with a high stress level and subsequent exhaustion. Most of the participants reported that the course provided structure to the rest of the day. This routine was hard to follow in the beginning, but after a while it appeared to make life easier for several of the participants. However, a few had problems getting to school on time.

Meeting frequently at school was by many evaluated as crucial for learning new social skills as well as computer skills. The process seemed to be strengthened by the context which invited 'normal' functioning. As one participant said: 'it was terribly stressful, especially the first month, but it was worth it.' In this first month, several participants experienced a high level of stress mainly because of their old dysfunctional patterns. At this phase, the computer, for several, represented a safe place whenever a pause from socializing was needed.

\section{Computerphobia}

To most of the participants, the learning process was facilitated by the heterogeneous nature of the group in terms of age, computer skills, and life experience. Some had never touched a PC before because of computerphobia, ${ }^{22}$ and they expressed fear that their classmates would think they were stupid. However, the psychoeducation sessions underlined the importance of recognizing and accepting an individual learning pace. Liz, a computer phobic, in one session released her tension by a joke, imitating her neighbor's 'racing sound', in contrast to the beat of her 2-finger search system. Later in the course, she could listen to his high speed sound without feeling inferior. Some participants reported a major improvement in concentration. They learned to focus and refocus and to accept their concentration problems instead of getting angry. They learned that blaming themselves would only make things worse. Thus they experienced a dual learning process: learning computer skills and learning psychosocial skills.

\section{Meeting other participants with similar challenges}

In addition to the psychoeducative aspects of the course, meeting others in a similar situation was described as an important factor. The group could be described as spontaneously supportive. Self-assertive techniques and skills of constructively providing negative feedback were not easy to practice. Psychoeducation facilitated the expression and discussion of current emotions, and some described a new feeling of release, since they did not have to hide their emotional arousal. To offer help was usually easier than to ask for help. Asking for help was initially either associated with bothering others, or a fear of being judged as stupid. To address these challenges, most of the students appreciated participating in behavioral experiments, such as to give eye-contact or expressing their opinion or their needs to a classmate or in front of the entire group. Talking about emotion and regulation 'became almost as natural as talking about handling a computer,' one participant reported. All the participants stated that the course had helped them 
become more aware of their own psychological functioning in general.

The classes were kept in an informal tone, thus fostering a safe and positive learning environment. ${ }^{32}$ Most of the participants said they felt safe. As Michael stated: 'everyone knows, and that makes it easier for me to accept experiencing some discomfort during class. I do not need to be alert all the time. I have got time to think about other things.' Several of the participants experienced problems with panic attacks. The psychologist or the teacher followed up when somebody left in panic, in order to assist with coping. Michael reported how, during the course, he had learned to handle his panic attacks. After the first attack taking place during class had been worked through individually, Michael allowed the psychologist to give the group a short explanation. This made it easier for Michael to return to the classroom afterwards. Then the panic circle ${ }^{33}$ was introduced as one of the first topics of psychoeducation. Basic emotions were explained, as were functional and dysfunctional ways of regulating emotions. Trying to hide distress was discussed as a safety behavior which caused a lot of stress, and they understood that worries and catastrophic thoughts made things worse. After 2 weeks, Michael finally managed to stay in the classroom throughout an attack. He felt that the group comforted him, and someone said to him: 'You know, it's not dangerous, it's just stress,' and they all applauded when the attack had passed. Michael was still quite exhausted, but smiling, 'I feel like a hero,' he said afterwards. The group also told him that they were hardly aware that he was experiencing an attack.

As the course progressed, talking about emotional topics became more normal and less stigmatizing not only in the classroom, but for some participants also outside the classroom. After a while, some of the participants talked without shame about their anxiety in the cafeteria, as if it were just a funny story. Some reported how they transferred their new knowledge to other situations, where the psychologist or teacher was not present. For instance, when Ann revealed to Ben that she did not dare to buy a cup of tea in the cafeteria because her hands were shivering too much, Ben told her that he did not dare to go there at all. Together, they developed a strategy using what they had learned about attention focus. Ben told Ann that he had never seen her hands shiver when she was absorbed in a computer task. They decided to go to the cafeteria together, not focusing on anxiety and instead talking about what they would like to eat and drink. When Ann began shivering, both laughed. The problem was easily solved; Ben took both cups to the table, spilling some tea on the floor, and they laughed even more. At the end of the course, Ann was able to buy her own tea.
Cilia had formerly attended a cognitive group for social anxiety at an outpatient clinic. She described the difference she felt existed between the two therapeutic settings: 'In a clinic, you feel segregated, you feel like a failure when others look at you and you get shaky, you feel like an idiot. Here I feel I'm almost normal. There are ordinary people here, and I am one of them. Being with classmates is very important; we meet at school every day and talk about everyday things, so anxiety becomes an everyday thing, too. It's not so scary any more, at least not here. However, it's still difficult to go to other places, where people don't know.' For David, another participant, it was not so easy. 'I do understand with my brain, but my body is still very tense. But I can see a way now, and I have decided to walk this way, even if it will take some time.'

As a result of having their self-esteem increased during the course, several participants told about their initiatives to expand their networks by refreshing old friendships or building new ones. Some did this by using the Internet (for instance, Facebook); others relied more on face-to-face contacts.

\section{Further occupational rehabilitation}

Seven of the 13 completers wanted to proceed with further occupational rehabilitation after the course. They all realized that they had to continue to exercise to strengthen their new coping patterns. Some wanted to attend a regular PC course at the same school in order to get a more formal qualification and to get more exercise with anxiety coping. Most of the participants experienced a need for a follow up, drawing on similar techniques as those used in the present course. Although 5 of the 13 completers were on permanent disability allowance, they still reported benefits from the course in the form of experiencing a better quality of life after having completed the course.

The participants who had dropped out half way still attended the final individual interview to discuss their experiences with the course. They typically gave reasons unrelated to the course for dropping out. All expressed a wish to attend the next course, as did those who felt 11 weeks was too short. Even the one who fulfilled the computer course without participating in psychoeducation wished to attend a new course, which included psychoeducation.

\section{The teacher's experiences}

The teacher underlined that the psychoeducation sessions had increased her understanding of the nature of social anxiety and some central challenges for social anxiety sufferers. 
She enjoyed having been able to contribute to considerable positive changes. In fact, she continued having contact with several of the participants after the course, who asked for further support on Facebook. The teacher was also invited to join a Facebook group initiated by the participants. She observed that they continued to make use of illustrations mapping functional and dysfunctional processes and other therapeutic tools discussed in the course. The teacher made the point that: 'A figure is easy to understand and to remember, so simple yet so important for improving functioning and communication.' She felt that 'psychoeducation created a common platform of knowledge about normal feelings, especially the negative ones.' In her experience, CBT provided a system of concepts which facilitated communication between the participants about current everyday feelings and problems. For instance, the participants all knew what it meant 'to be in the bubble', a term used in the class for negative self-focus. The teacher felt that just mentioning these few words for a student immediately created mutual understanding, and often was accepted with a smile as a reminder to direct focus out. Humor made the discomfort of the 'bubble' less lonely and less threatening.

The teacher said she appreciated the cognitive model especially 'because it is so close to everyday life experience.' She asserted that knowledge about the cognitive model could be useful for nearly everybody. 'You become more conscious, and can better understand both yourself and others.' After being a part of the course, she could understand how difficult it was for a person suffering from social anxiety to enter a cafeteria - even if the inner storm was hardly visible for others. 'Now I know why,' the teacher remarked. When asked about how the computer course would have functioned without psychoeducation, she replied: 'It would not have worked, with all their anxieties and negative beliefs.'

\section{Discussion}

\section{Main findings}

The 2 main research questions in this explorative study were: (1) Do the participants report (ie, in the interviews) benefits from participating in the course? And (2) Do the participants wish to continue with occupational rehabilitation after the course? The results confirm that integrating psychoeducation sessions in a basic computer skills course was perceived to be beneficial by the participants. First, many of the participants felt that they benefited from the psychoeducation in itself. Understanding the cognitive model and learning CBT techniques for coping with stress, anxiety, and other difficult feelings, was seen as useful by most. Experiencing support from other people with similar challenges was also reported to be beneficial. In addition, many of the participants emphasized the gains made from learning psychosocial skills and basic computer skills in the same course. Being a student at a school seemed to increase the participants' self-esteem and their optimism about future possibilities. It provided a structure, which many of the participants felt they needed and which made them feel better. Learning how to use a computer was seen as beneficial by the participants. ${ }^{22}$ It seems clear that some of the participants would not have been able to attend an ordinary computer skills class, due to their problems with social anxiety and other mental health issues. By attending the psychoeducation sessions with the students, the computer skills teacher became a competent supporter, which seemed crucial for the positive effect of the intervention. By integrating sessions on psychoeducation and psychosocial skills into a computer course, the students were able to overcome some of their anxieties. Seven of the 13 completers indicated that they wanted to continue with some sort of occupational rehabilitation after the course, and some said that they would like to continue to work with computers. Thus, they had increased computer self-efficacy beliefs. ${ }^{34}$

\section{Shame and empowerment}

Traditionally, psychological treatment is provided in a clinic, separated from 'real life'. Emotional problems have been regarded as a type of disease, often associated with shame and stigmatization. People suffering from social anxiety are especially vulnerable to feeling humiliated and stigmatized, and it is easy to understand that it is difficult for them to meet at a psychiatric clinic. On the other hand, 'real life' has often excluded and stigmatized negative emotional expressions as weakness and labelled those who were not in full control of their emotions as 'inferior' or 'sick'. Our findings suggest that empowering the participants by providing knowledge appeals to the participants. Not only do they report that the course has helped them cope with their anxiety, but the participants have also developed a supporting self-help group.

\section{Psychoeducation}

Learning about functional processes leading to coping, as well as dysfunctional processes producing symptoms, may have had a normalizing and de-stigmatizing effect on the participants. Psychological knowledge about anxiety and other processes was provided in terms of metacognitive illustrations which were easy to understand and to remember. Subsequently, the participants reported that anxiety was no longer experienced as a disease but rather as an understandable 
process one could regulate. This may have created a common platform for sharing emotional experiences. The classroom setting as well as the CBT approach may explain the reported experiences of reduced fear of feeling embarrassed, as well as the virtual disappearance of a negative self-focus. Crucial anxiety-maintaining processes vanished, at least in the classroom situation.

\section{Study limitations}

This study has some limitations. It is a qualitative explorative study, based on a relatively small sample of participants. Although we believe the results are promising, our design does not allow for a statistical testing of the outcomes of the course. The sample was rather heterogeneous in terms of psychiatric diagnoses and psychiatric comorbidity. The positive subjective impact reported could be either increased or decreased in a new sample with participants without any comorbidity. However, the heterogeneity of the sample added a naturalistic flavor to the study and, we believe, its external validity. The CBT treatment manual for social anxiety disorder had to be modified to accommodate the participants' multifaceted problems. Thus, although many elements were borrowed from the CBT manual for treatment of social anxiety, we were not able to test the impact of the standardized CBT manual in this study.

\section{Conclusions}

In this study, we carried out a basic computer skills course combined with psychoeducation. The participants suffered from social anxiety in addition to various other mental health challenges. In interviews after the end of the course, the participants were generally very positive about the integration of psychoeducation in the computer skills course, and 13 of 16 completed the course. Most participants stated that they felt they had benefited significantly from the psychoeducation sessions, and that learning basic computer skills was important for their self-esteem. After the course, 7 of the 13 completers wanted to go on with further occupational rehabilitation. The study represents a productive human computer interaction, and suggests that a CBT-based program assisting the learning of computer skills may promote occupational rehabilitation by reducing social anxiety and increasing psychosocial coping skills. The course represents an alternative method for dissemination of CBT that may suit the needs of patients reluctant to come to traditional outpatient clinics. Future controlled studies are needed to confirm these initial encouraging findings.

\section{Acknowledgments}

The directors of the school KunnskapiNord, and the computer skills teacher are gratefully acknowledged for their commitment to the project. We also thank the Norwegian Labour and Welfare Authority (NAV Tromsø) for funding the computer courses, and the North Norway Regional Health Authority (Helse Nord RHF) for funding the research. Also, thanks to the participants who despite considerable anxiety agreed to contribute to the development and evaluation of the course.

\section{Disclosure}

The authors report no conflict of interest.

\section{References}

1. Kringlen E, Torgersen S, Cramer V. A Norwegian psychiatric epidemiological study. Am J Psychiatry. 2001;158:1091-1098.

2. Stein MB, Stein DJ. Social anxiety disorder. Lancet. 2008;371: $1115-1125$.

3. Keller MB. The lifelong course of social anxiety disorder: a clinical perspective. Acta Psychiatr Scand. 2003;417(Suppl 1):85-94.

4. Ohayon MM, Schatzberg AF. Social phobia and depression: prevalence and comorbidity. J Psychosom Res. 2010;68:235-243.

5. Fehm L, Pelissolo A, Furmark T, Wittchen HU. Size and burden of social phobia in Europe. Eur Neuropsychopharmacol. 2005; $15: 453-462$.

6. Schneier FR, Johnson J, Hornig CD, Liebowitz MR, Weissman MM. Social phobia. Comorbidity and morbidity in an epidemiologic sample. Arch Gen Psychiatry. 1992;49:282-288.

7. Acarturk C, de Graaf R, van Straten A, Have MT, Cuijpers P, Social phobia and number of social fears, and their association with comorbidity, health-related quality of life and help seeking: a population-based study. Soc Psychiatry Psychiatr Epidemiol. 2008;43:273-279.

8. Lépine JP, Pélissolo A. Social phobia and alcoholism: a complex relationship. J Affect Disord. 1998;50(Suppl 1):S23-S28.

9. Kashdan TB, McKnight PE, Richey JA, Hofmann SG. When social anxiety disorder co-exists with risk-prone, approach behavior: investigating a neglected, meaningful subset of people in the National Comorbidity Survey-Replication. Behav Res Ther. 2009;47:559-568.

10. Acarturk C, Smit F, de Graaf R, van Straten A, Ten Have M, Cuijpers P. Economic costs of social phobia: a population-based study. J Affect Disord. 2009;115:421-429.

11. Patel A, Knapp M, Henderson J, Baldwin D. The economic consequences of social phobia. J Affect Disord. 2002;68:221-233.

12. Tolman RM, Himle J, Bybee D, Abelson JL, Hoffman JM, Van Etten-Lee M. Impact of social anxiety disorder on employment among women receiving welfare benefits. Psychiatr Serv. 2009;60:61-66.

13. Erickson SR, Guthrie S, Vanetten-Lee M, et al. Severity of anxiety and work-related outcomes of patients with anxiety disorders. Depress Anxiety. 2009;26:1165-1171.

14. Fedoroff IC, Taylor S. Psychological and pharmacological treatments of social phobia: a meta-analysis. J Clin Psychopharmacol. 2001;21: 311-324.

15. Stangier U, Heidenreich T, Peitz M, Lauterbach W, Clark DM. Cognitive therapy for social phobia: individual versus group treatment. Behav Res Ther. 2003;41:991-1007.

16. Lysaker PH, Davis LW, Bryson GJ, Bell MD. Effects of cognitive behavioral therapy on work outcomes in vocational rehabilitation for participants with schizophrenia spectrum disorders. Schizophr Res. 2009;107:186-191. 
17. Lambeek LC, van Mechelen W, Dirk L, Knol DL, Loisel P, Anema JR. Randomised controlled trial of integrated care to reduce disability from chronic low back pain in working and private life. Brit Med J. 2010; 340:c1035.

18. Clark DM, Wells A. A cognitive model of social phobia. In: Heimberg MM, Liebowitz M, Hope D, Schneider FR, editors. Social Phobia: Diagnosis, Assessment and Treatment. New York: Guilford Press; 1995:69-93.

19. Rapee RM, Heimberg RG. A cognitive-behavioral model of anxiety in social phobia. Behav Res Ther. 1997;35:741-756.

20. Wells A. Metacognitive Therapy for Anxiety and Depression. New York: Guilford Press; 2009.

21. Okasha A. Would the use of dimensions instead of categories remove problems related to subthreshold disorders? Eur Arch Psychiatry Clin Neurosci. 2009;259(Suppl 2):S129-S133.

22. Wilson B. Redressing the anxiety imbalance: computerphobia and educators. Behav Inform Technol. 1999;18:445-453.

23. Löhr H, Rosenvinge JH, Gammon D, Johnson JA. Kan Internett hjelpe mennesker med alvorlige psykiske lidelser? Brukererfaringer i et klinisk perspektiv. May using the Internet help patients with serious psychiatric disorders? Patients' experiences in a clinical perspective. J Norwegian Psychol Ass. 2002;39:514-519.

24. Bargh JA, McKenna KY. The internet and social life. Annu Rev Psychol. 2004;55:573-590.

25. Löhr H, Wynn R, Rosenvinge JH. E-therapy as an adjunct to face-to-face therapy in the treatment of patients suffering from chronic psychiatric disorders. J Inform Technol Healthcare. 2007;5:67-79.
26. Caplan SE. Relations among loneliness, social anxiety, and problematic Internet use. Cyberpsychol Behav. 2007;10:234-242.

27. Campbell AJ, Cumming SR, Hughes I. Internet use by the socially fearful: addiction or therapy? Cyberpsychol Behav. 2006;9:69-81.

28. Bessière K, Pressman S, Kiesler S, Kraut, R. Effects of internet use on health and depression: a longitudinal study. J Med Internet Res. 2010; 28,12,e6.

29. American Psychiatric Association. Diagnostic and Statistical Manual of Mental Disorders (DSM-IV). 4th ed. Washington, DC, American Psychiatric Publishing; 2011.

30. Cox BJ, Pagura J, Stein MB, Sareen J. The relationship between generalized social phobia and avoidant personality disorder in a national mental health survey. Depress Anxiety. 2009;26:354-362.

31. Graneheim UH, Lundman B. Qualitative content analysis in nursing research: concepts, procedures and measures to achieve trustworthiness. Nurse Educ Today. 2004;24:105-112.

32. Xiao L, Carrol JM. Fostering an informal learning community of computer technologies at school. Behav Inform Technol. 2007;26: 23-36.

33. Clark DM. A cognitive approach to panic. Behav Res Ther. 1986;24 $461-470$.

34. Torkzadeh R, Pflughoeft K, Hall J. Computer self-efficacy, training effectiveness and user attitudes: An empirical study. Behav Inform Technol. 1999;18;299-309.
Journal of Multidisciplinary Healthcare

\section{Publish your work in this journal}

The Journal of Multidisciplinary Healthcare is an international, peerreviewed open-access journal that aims to represent and publish research in healthcare areas delivered by practitioners of different disciplines. This includes studies and reviews conducted by multidisciplinary teams as well as research which evaluates the results or conduct of such teams or

\section{Dovepress}

healthcare processes in general. The journal covers a wide range of areas and welcomes submission from practitioners at all levels, from all over the world. The manuscript management system is completely online and includes a very quick and fair peer-review system. Visit http://www.dovepress.com/testimonials.php to read real quotes from published authors. 